\title{
COMO A CÉLULA ÓSSEA RECONHECE O ESTÍMULO MECÂNICO?
}

\author{
HOW DO BONE CELLS SENSE MECHANICAL LOADING?
}

Carlos Vinícius Buarque de Gusmão', William Dias Belangero²

\section{RESUMO}

Sob a influência da gravidade, o tecido ósseo sofre maior ou menor deformação de acordo com a intensidade das atividades da vida diária. Sabe-se que as atividades que resultam em impacto são as que mais estimulam a osteogênese e assim reduzem a perda de massa óssea. Conhecer como as células ósseas reconhecem a deformação mecânica imposta ao osso e iniciam uma série de reações bioquímicas em cadeia é de fundamental importância para o desenvolvimento de práticas terapêuticas e preventivas na atividade ortopédica. Ainda há um longo caminho para o entendimento de todo esse processo, mas o conhecimento atual progrediu bastante e há pesquisas com finalidade terapêutica. O sinal mecânico para ser transformado em biológico (mecanotransdução) deve ser amplificado no nível celular pela estrutura histológica do tecido ósseo, gerando tensões em proteínas da membrana celular (integrinas) e alterando a estrutura espacial dessas proteínas. Essa alteração ativa ligações entre elas e o citoesqueleto, originando as adesões focais, locais onde proteínas citoplasmáticas são recrutadas para facilitar as reações bioquímicas. A quinase de adesão focal (FAK) é a principal delas, sendo autoativada após sofrer alteração estrutural pelas integrinas. A FAK ativada incita reações em cascata, resultando na ativação da ERK-1/2 e da Akt, proteínas que, junto com a FAK, regulam a produção da massa óssea. Acredita-se que o osteócito seja a célula óssea responsável por reconhecer o estímulo mecânico e transmiti-lo aos osteoblastos e osteoclastos. Canais iônicos e gap junctions são cogitados como meios de comunicação intercelular para a transmissão bioquímica do estímulo mecânico. Esses eventos ocorrem continuamente no tecido ósseo e regulam a remodelação óssea.

Descritores - Mecanotransdução celular; Osteogênese; Estresse mecânico; Suporte de carga; Osteócitos; Osteoblastos; Junções gap; Canais iônicos

\section{ABSTRACT}

Influenced by gravidity, bone tissue experiences stronger or lighter deformation according to the strength of the activities of daily life. Activities resulting in impact are particularly known to stimulate osteogenesis, thus reducing bone mass loss. Knowing how bone cells recognize the mechanical deformation imposed to the bone and trigger a series of biochemical chain reactions is of crucial importance for the development of therapeutic and preventive practices in orthopaedic activity. There is still a long way to run until we can understand the whole process, but current knowledge has shown a strong progression, with researches being conducted focused on therapies. For a mechanical sign to be transformed into a biological one (mechanotransduction), it must be amplified at cell level by the histological structure of bone tissue, producing tensions in cell membrane proteins (integrins) and changing their spatial structure. Such change activates bindings between these and the cytoskeleton, producing focal adhesions, where cytoplasmatic proteins are recruited to enable easier biochemical reactions. Focal adhesion kinase (FAK) is the most important one being self-activated when its structure is changed by integrins. Activated FAK triggers a cascade of reactions, resulting in the activation of ERK-1/2 and Akt, which are proteins that, together with FAK, regulate the production of bone mass. Osteocytes are believed to be the mechanosensor cells of the bone and to transmit the mechanical deformation to osteoblasts and osteoclasts. Ionic channels and gap junctions are considered as intercellular communication means for biochemical transmission of a mechanical stimulus. These events occur continuously on bone tissue and regulate bone remodeling.

Keywords - Mechanotransduction cellular; Osteogenesis; Stress mechanical; Weight-bearin; Osteocytes; Osteoblasts; Gap junctions; Ion channels

1 - Aluno de Graduação da Faculdade de Ciências Médicas da Universidade Estadual de Campinas-Unicamp.

2 - Professor Livre-Docente do Departamento de Ortopedia e Traumatologia da Faculdade de Ciências Médicas da Universidade Estadual de Campinas- Unicamp.

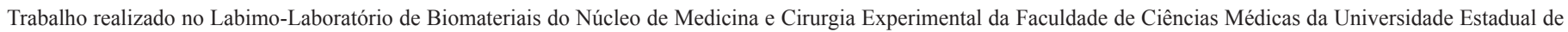
Campinas-Unicamp.



Declaramos inexistência de conflito de interesses neste artigo 


\section{INTRODUÇÃO}

A manutenção da massa óssea é regulada por diversos estímulos, que podem ser agrupados em bioquímicos (os fatores de crescimento e hormônios) e mecânicos. A respeito destes últimos, sabe-se que imobilização prolongada e situações de diminuição da gravidade provocam redução da massa óssea; já o impacto sobre o tecido ósseo, provocado, por exemplo, pela prática de exercícios físicos, aumenta a massa óssea ${ }^{(1-10)}$.

Independente da modalidade de estimulação mecânica (ultrassom de baixa potência, fluxo de fluido, centrifugação, aplicação estática de carga, vibração ou campo eletromagnético), ela é reconhecida pelas células ósseas após um processo denominado mecanotransdução, responsável por produzir reações bioquímicas a partir de um fenômeno mecânico (físico), determinando uma resposta celular, que pode ser de produção ou reabsorção óssea ${ }^{(8,10-13)}$. Neste manuscrito, serão discutidos os fenômenos e as teorias sobre essa área da ortopedia parcialmente compreendida.

\section{Amplificação do estímulo mecânico}

A função primordial do tecido ósseo é de suportar a carga do corpo. Segundo a lei de Wolff apud Duncan e Turner ${ }^{(8)}$, esse tecido é capaz de se adaptar às solicitações mecânicas produzidas pelo peso do indivíduo e pelas atividades físicas que causam deformação de todo o esqueleto. Normalmente, a deformação sofrida pelo tecido ósseo durante a locomoção varia de 0,04 a $0,3 \%$ e raramente excede $0,1 \%{ }^{(14,15)}$. Entretanto, estudos in vitro mostraram que a deformação necessária para as células ósseas responderem ao estímulo mecânico é 10 a 100 vezes maior do que o necessário para o tecido ósseo como um todo ( 1-10\%). Se a mesma deformação relativa (strain) usada para estimular as células ósseas fosse utilizada no tecido ósseo, este sofreria fratura ${ }^{(8,16)}$. Essa aparente contradição entre a estimulação nos níveis macroscópico e microscópico (celular) foi explicada e justificada pelo modelo matemático experimental desenvolvido por You et $a^{(16)}$, no qual o sistema canalicular em que as células ósseas (osteócitos) estão inseridas serve como amplificador da deformação mecânica gerada pela atividade física.

\subsection{Anatomia histológica óssea}

A estrutura dos ossos longos pode ser entendida esquematicamente como um cilindro, contendo vários cilindros dentro dele, os canais de Havers ou canais haversianos, que se comunicam entre si por meio dos canais de Volkmann. As paredes que formam os canais de Havers são dispostas radialmente, sendo denominadas lamelas. Estas são compostas por matriz extracelular (MEC) óssea, que é constituída basicamente de hidroxiapatita (componente inorgânico) e colágeno tipo I (componente orgânico). A MEC óssea forma uma estrutura que aprisiona os osteócitos nas lacunas dentro das lamelas. Os osteócitos possuem prolongamentos de seu citoplasma, denominados processos citosplasmáticos (ou dendritos), envolvidos pelos canalículos (Figura 1). Entre a parede canalicular e o processo citoplasmático, existe o espaço pericelular, permeado por um fluido. No espaço pericelular existe uma matriz orgânica pericelular (PEM) sustentada por fibrilas transversas, que ancoram e centralizam o processo citoplasmático do osteócito em seu canalículo ${ }^{(16,18)}$ (Figura 2).

\subsection{Força de arrasto e estresse de cisalhamento}

De forma simplificada, quando o osso é deformado, cria-se um gradiente de pressão no complexo sistema de cilindros, resultando em fluxo do fluido dentro do espaço pericelular dos processos citoplasmáticos, exer-

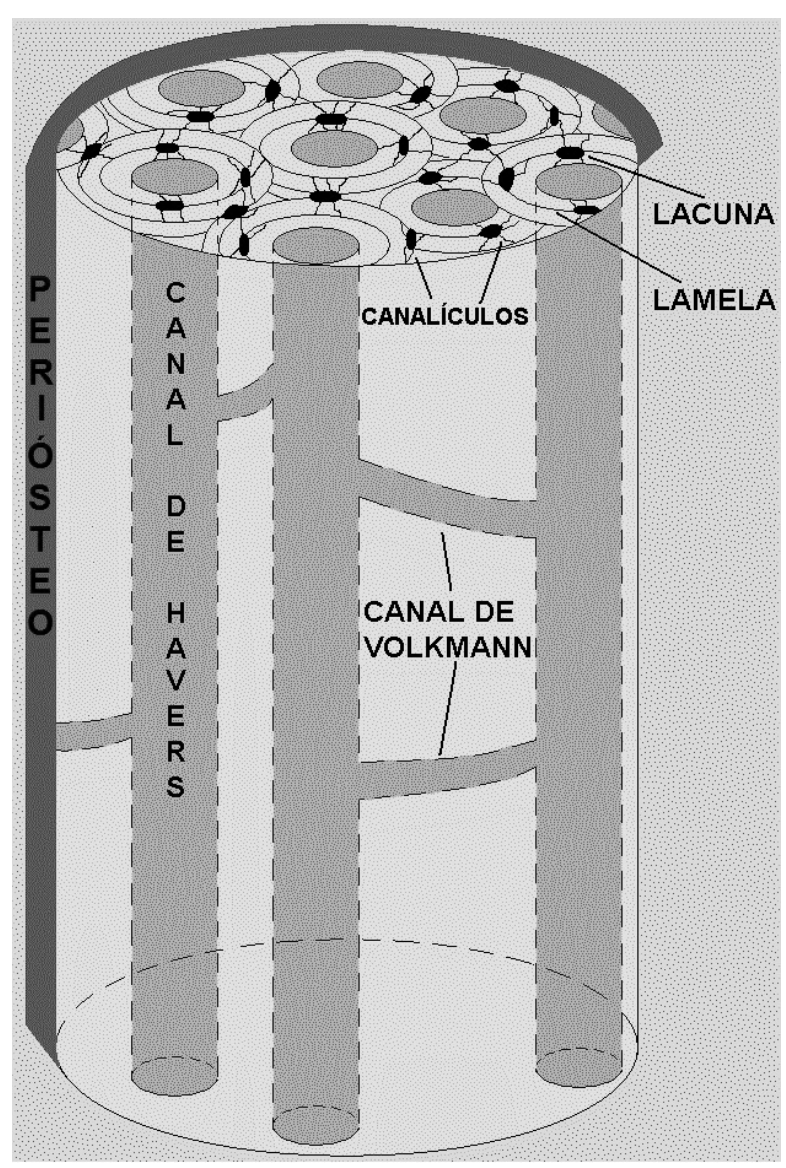

Figura 1 - Anatomia histológica óssea 


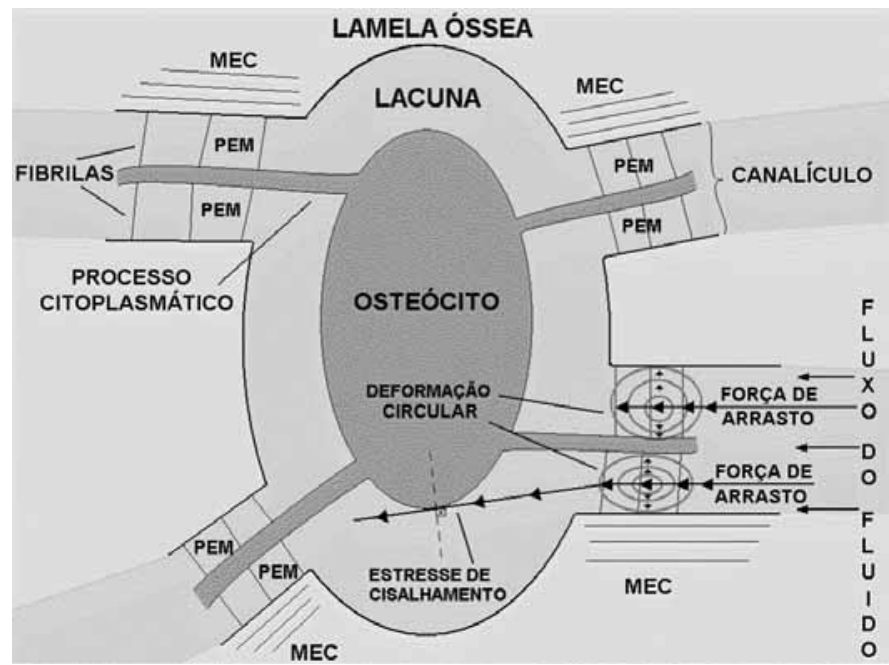

Figura 2 - Amplificação do estímulo mecânico. A deformação mecânica do tecido ósseo produz fluxo do fluido, que, no nível dos canalículos ósseos, exerce força de arrasto sobre os processos citoplasmáticos e as paredes dos canalículos ósseos. Além disso, o fluxo do fluido exerce uma força tangencial sobre a membrana plasmática do osteócito, produzindo estresse de cisalhamento

cendo força de arrasto (drag force) sobre a PEM. A força de arrasto é o resultado da força de atrito e da pressão sobre um corpo que transita dentro de um meio líquido. Nesse caso, o que transita é o líquido (fluido ósseo) sobre a PEM, mas a força de arrasto é produzida do mesmo modo.

A estrutura histológica do osso permite que a força de arrasto produza deformações circulares (hoop strains) no sistema membrana-citoesqueleto dos processos celulares dos osteócitos, deformações estas que são de 20 a 100 vezes maiores (ou mais) do que a deformação do tecido ósseo como um todo. As deformações circulares são as tensões normais (i.é., a tensão que forma um ângulo de $90^{\circ}$ com a tangente) a um corpo com simetria circular. Em outras palavras, as deformações circulares produzem forças de compressão e de tração sobre o tecido e, quanto maior a magnitude ou a frequência do estímulo, maior a amplificação da deformação (Figura 2).

$\mathrm{O}$ estresse de cisalhamento (shear stress ou tensão tangencial) é a deformação que um corpo sofre quando sujeito à ação de forças cortantes (tangenciais). Embora You et $a^{(16)}$ não tenham considerado o estresse de cisalhamento como responsável por amplificar a deformação do tecido ósseo em nível celular, na visão de vários autores, sua importância não deve ser ignorada ${ }^{(8,10-12,16,19-21)}$. Os dois tipos de deformação celular devem contribuir para o estímulo mecânico celular (Figura 2).

\section{A célula mecanossensora}

Há três tipos principais de células no tecido ósseo: osteoblastos, osteócitos e osteoclastos. Durante décadas, os osteoblastos e os osteoclastos foram considerados os protagonistas da remodelação óssea e, por esse motivo, foram muito mais estudados do que os osteócitos, que correspondem a $90-95 \%$ de todas as células ósseas. Investigando o comportamento dos osteócitos, observou-se que, assim como os osteoblastos, eles também respondem ao estímulo mecânico, exibindo a ativação basicamente das mesmas proteínas que os osteoblastos $^{(17,22)}$. Desde então, pergunta-se qual é o principal mecanossensor do tecido ósseo: o osteoblasto ou o osteócito?

Embora ainda não exista nenhuma comprovação científica definitiva, é amplamente divulgado que os osteócitos são as células que orquestram a remodelação óssea ${ }^{(8,22-24)}$, liberando mediadores bioquímicos que regulam a atividade dos osteoblastos e dos osteoclastos. Falando a favor dessa teoria, observou-se que os osteócitos produzem prostaglandinas - mediadores da atividade dos osteoblastos e osteoclastos - mais rápido do que os osteoblastos após estímulo mecânico ${ }^{(25)}$; e que osteócitos submetidos a fluxo de fluido estimulam a atividade osteogênica dos osteoblastos ${ }^{(26)}$. É esperado que os osteoblastos sejam sensíveis ao estímulo mecânico, já que os osteócitos derivam dessas células. Além disso, as células ósseas não são as únicas capazes de realizar a mecanotransdução. Fibroblastos ${ }^{(27)}$, $\operatorname{condrócitos~}^{(28)}$, cardiomiócitos $^{(29)}$, células endoteliais ${ }^{(30)}$ e rabdomiócitos ${ }^{(31)}$ também possuem essa capacidade. No entanto, para a comunidade científica, é mais lógico que os osteócitos sejam mais solicitados como mecanossensores no tecido ósseo do que os osteoblastos, pois eles fazem parte do sistema canalicular de amplificação da deformação mecânica, enquanto que os osteoblastos se localizam na periferia do tecido ósseo, no periósteo.

\section{Piezoeletricidade}

O efeito piezoelétrico é uma resposta biológica ao estímulo mecânico conhecida há bastante tempo, documentada por Fukada e Yasuda em 1957 após observarem produção de carga elétrica negativa em áreas de compressão no osso e de carga elétrica positiva nas áreas de tração ${ }^{(32)}$. Esse efeito foi reproduzido e mensurado por outros autores, como Butcher et $a l^{(33)}$ e Qin et $a l^{(34)}$; a hipótese para esse fenômeno foi divulgada por Duncan e Turner ${ }^{(8)}$, os quais acreditavam que o fluxo do fluido, 
gerado pelas tensões mecânicas, produzia potenciais de corrente (streaming potentials), modulando a resposta celular. Atualmente, sabe-se que o efeito piezoelétrico não é a mecanotransdução; ele é apenas um marcador do fluxo do fluido. Este provoca a ativação de canais iônicos mecanossensíveis, principalmente os de potássio e de cálcio, induzindo fluxo iônico na célula óssea, o que resulta em alteração do potencial da membrana celular, podendo ser positivo (despolarização) ou negativo (hiperpolarização). A célula óssea pode, rapidamente, identificar as características do estímulo mecânico e responder eletrofisiologicamente em modos diferentes, com maior ou menor ativação dos canais iônicos, resultando em hiperpolarização ou despolarização da membrana plasmática. O que determina a intensidade da ativação dos canais iônicos não está claro, mas sabe-se que a intensidade e a frequência do estímulo mecânico, bem como a velocidade do fluxo do fluido, regulam a ativação desses canais. Sabe-se que a hiperpolarização está associada à osteogênese, enquanto a despolarização, com a reabsorção óssea. Além de regular a resposta celular ao estímulo mecânico, acredita-se que a ativação de canais iônicos transmite, bioquimicamente, a deformação mecânica para osteócitos vizinhos, osteoblastos e osteoclastos $^{(12,33-39)}$.

\section{Mecanotransdução}

A mecanotransdução pode ser interpretada como o processo de produção de uma reação bioquímica a partir de um estímulo mecânico. As reações bioquímicas em cadeia induzidas pelo estímulo mecânico atuam em nível celular e podem causar inibição da apoptose, aumento da proliferação celular, alteração na migração celular, entre outros efeitos.

Quando um estímulo mecânico externo produz deformação do tecido ósseo, ocorrem, em nível celular, deformação circular e estresse de cisalhamento, que atuam sobre a membrana plasmática dos osteócitos e são transmitidos por toda a célula através de uma complexa rede que conecta a membrana plasmática ao núcleo da célula, denominada de sistema matriz extracelular (e pericelular)-integrinas-citoesqueleto-núcleo. Duncan e Turner ${ }^{(8)}$ idealizaram um modelo de mecanotransdução, no qual este sistema é fundamental; o estresse mecânico provoca tensão entre os constituintes desse sistema, permitindo a transmissão da deformação desde a MEC até o núcleo das células. Elaborando esse modelo à luz dos conhecimentos atuais, os autores desta revisão acreditam que seu funcionamento seja como o de um sistema de alavancas com múltiplos pontos de apoio, que representam as interações entre as moléculas que compõem a matriz extracelular/pericelular (colágeno, fibronectina e fibrilas), as diferentes subunidades das integrinas, o citoesqueleto (actina, vinculina, talina, paxilina e $\alpha$-actinina) e a membrana nuclear ${ }^{(8,17,18)}$. Portanto, os pontos de apoio podem ser moldados de acordo com o tipo e a quantidade de moléculas interagindo entre si, o que permite diversos tipos de transmissão da deformação mecânica.

\subsection{As integrinas}

Em cada região do sistema MEC/PEM-integrinascitoesqueleto-núcleo, existem proteínas interagindo com seus constituintes. A região das integrinas é a mais compreendida, sendo considerada a mais importante para a mecanotransdução. O nome integrina refere-se a sua função de integrar o interior da célula (citoesqueleto) com seu exterior (MEC e PEM). As integrinas são glicoproteínas transmembrana heterodiméricas de adesão celular compostas por subunidades $\alpha$ e $\beta$. No ser humano, há 24 tipos de integrinas bem estabelecidos, resultado de combinações dos 18 tipos de subunidades $\alpha$ e oito tipos de subunidades $\beta$. As diferentes combinações das subunidades $\alpha$ e $\beta$ determinam a especificidade de ligação das integrinas aos componentes da MEC e do citoesqueleto e às proteínas citoplasmáticas, bem como o grau de afinidade para um mesmo ligante. Os osteoblastos expressam as subunidades $\alpha 2, \alpha 3, \alpha 4, \alpha 5$, $\alpha \mathrm{v}, \alpha 6, \beta 1, \beta 3$ e $\beta 5$ in vitro ${ }^{(40,41)}$, enquanto que, in vivo, a expressão das integrinas é restrita basicamente a $\alpha 3$, $\alpha 5, \alpha v, \beta 1$ e $\beta 3^{(42)}$. Nessas células, as subunidades que, sabidamente, respondem ao estímulo mecânico são $\alpha 2$, $\alpha 5$, $\beta 1$ e $\beta 3$; e os heterodímeros comprovadamente envolvidos na mecanotransdução são $\alpha 5 \beta 1$ e $\alpha v \beta 3$.

Acredita-se que, após a deformação mecânica da membrana plasmática, ocorre alteração conformacional das integrinas, criando, em sua estrutura química, sítios de alta afinidade para reações químicas, resultando em ligações com outras integrinas e componentes do citoesqueleto. Em outras palavras, o estímulo mecânico funcionou como uma enzima, que catalisa a reação bioquímica. Ligações entre várias integrinas formam agrupamentos (clusters) que aumentam a avidez dessas proteínas para se ligar a outras moléculas. Os agrupamentos de integrinas se ancoram nos componentes do citoesqueleto, induzindo o remodelamento deste, formando uma estrutura especializada chamada de adesão focal (ou contato focal). Essa estrutura é di- 
nâmica, pois forma-se em resposta ao estímulo mecânico e desfaz-se em resposta à ausência desse estímulo. Localiza-se próximo à membrana plasmática e à MEC e recruta várias moléculas envolvidas na mecanotransdução: quinases de tirosina, canais iônicos, fosfolipase C, MAPK (mitogen-activated protein kinase), entre outras $^{(11,12,43-46)}$.

\subsection{As vias da quinase de adesão focal (FAK)}

De todas as moléculas que interagem com as integrinas nas adesões focais, a mais estudada e considerada fundamental na conversão do fenômeno mecânico em bioquímico é a quinase de adesão focal (FAK, focal adhesion kinase), uma proteína adaptadora, do grupo das quinases de tirosina, cuja estrutura lhe permite interagir com diversas proteínas, possibilitando a formação de múltiplos complexos proteicos. Essa característica pode aumentar a resposta celular, caso a atividade dos múltiplos complexos seja aditiva; ou pode incitar diferentes modalidades de resposta celular, caso a atividade dos complexos seja em vias diferentes.

Não está bem estabelecido se a FAK está sempre conectada às integrinas, ou se é recrutada pelas integrinas quando estas formam as adesões focais. Os autores deste manuscrito acreditam que as duas formas existem e possuem suas funções. Após a deformação das integrinas, a FAK deve ser deformada em sequência, sofrendo também alteração em sua estrutura, o que resulta em sua autofosforilação no resíduo de tirosina-397 (Tyr-397). Isso ativa a FAK, com a criação de um sítio de alta afinidade para ligação a proteínas que contêm o domínio SH2 (Src-homology-2), como Src e a subunidade p85 da PI3K (phosphatidylinositol 3kinase). Em sequência, a FAK ativada se conjuga com a Src ou com a PI3K, ativando as vias FAK-Src/Grb2/ Sos/Ras-Raf/MEK/ERK-1/2 e FAK/PI3K/Akt/NF-кB, respectivamente. A ERK-1/2 (extracellular signalregulated kinase-1/2) e a Akt são proteínas efetoras dessas vias, podendo exercer suas funções tanto no citoplasma quanto no núcleo da célula óssea. O que determina se essas proteínas, incluindo a FAK, estarão no núcleo ou no citoplasma não está bem estabelecido, mas as investigações sugerem que isso é determinado pela quantidade de proteína e a quantidade de proteína que está ativada. Especula-se que a localização nuclear implica aumento dos efeitos dessas proteínas (FAK, ERK-1/2 e Akt), que podem ser: indução da migração, proliferação e diferenciação celulares, e a inibição da apoptose $^{(8,10,20,30,47-54)}$ (Figura 3).

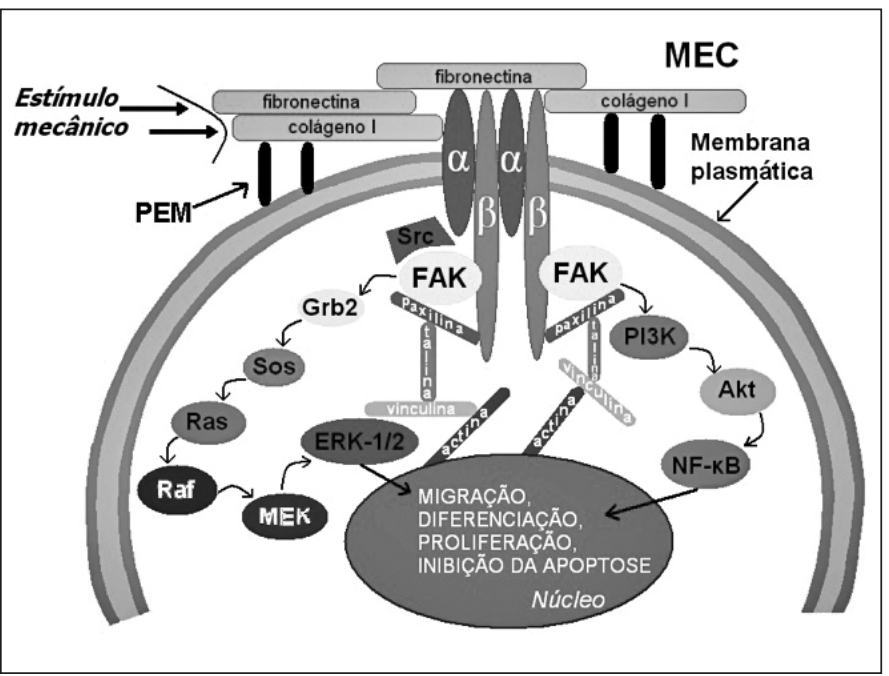

Figura 3 - Sinalização do estímulo mecânico FAK-dependente, em células ósseas. A FAK mantém íntima relação com as subunidades $\alpha$ e $\beta$ das integrinas, e com os componentes do citoesqueleto (actina, paxilina, talina e vinculina), que também estão em contato com o núcleo

\subsection{Transmissão bioquímica do estímulo mecânico para outras células}

Mesmo as células não deformadas pela força mecânica exibem resposta bioquímica semelhante à das que foram deformadas. Observou-se, nesses casos, a fosforilação (ativação) da conexina 43, responsável por ativar as gap junctions, que são estruturas de comunicação intercelular localizadas nos processos citoplasmáticos dos osteócitos. As gap junctions permitem a troca de íons e pequenas moléculas, principalmente prostaglandinas $\mathrm{E}_{2}\left(\mathrm{PGE}_{2}\right)$, entre osteócitos, e entre osteócitos e osteoblastos.

A ativação de canais iônicos também deve contribuir para a transmissão bioquímica do estímulo mecânico. A deformação mecânica provoca ativação e inativação de canais iônicos, principalmente de cálcio e potássio, que gera um potencial de ação negativo, com hiperpolarização da membrana, que é transmitido às células vizinhas, ativando reações intracelulares ${ }^{(26,35,37,55,56)}$.

Apesar de intrigante, este assunto foi pouco explorado, tendo o foco das investigações atuais se voltado principalmente para a via das integrinas.

\subsection{Mecanotransdução in vivo}

A maioria dos trabalhos realizados baseia-se em modelos experimentais in vitro ${ }^{(11,16,19,21,23,25,26,35,46)}$. A despeito da inegável contribuição desses trabalhos para orientação das pesquisas subsequentes, devem-se considerar as limitações de um estudo in vitro quando com- 
parado com a realidade, isto é, um estudo in vivo ${ }^{(57,58)}$. Em ossos com algum tipo de lesão, foi documentado o efeito benéfico do ultrassom de baixa potência (USbp), em acelerar a consolidação óssea ${ }^{(59-66)}$.

Os autores desta revisão desenvolveram um modelo de estudo em ratos, para avaliar o efeito "molecular" do tratamento diário por 20 minutos com o USbp nas tíbias intactas desses animais. As tíbias foram estimuladas, pelo menos, por uma semana. Após o tratamento, proteínas ósseas envolvidas na mecanotransdução (FAK, ERK-1/2 e Akt) foram mensuradas. Foi observado que o tratamento de longa duração com USbp aumentou a síntese da FAK e ERK-1/2 de maneira não cumulativa, ou seja, num determinado momento, a síntese dessas proteínas parou de aumentar, como se algo tivesse bloqueado os efeitos do USbp. A ativação da FAK, ERK$1 / 2$ e Akt foi precoce e, em alguns momentos, sustentada por 15 horas (apenas FAK e ERK-1/2), diferente do que ocorre quando se aplica um único estímulo. $\mathrm{O}$ encontro de maior quantidade de IRS-1 (insulin receptor substrate-1), uma proteína ativada por fatores de crescimento e hormônios, em um dos grupos estimulados, sugere que o USbp interfere em reações celulares mediadas por fatores de crescimento, assunto este controverso nos modelos in vitro e pouco investigado. Somando-se a isso, o aumento da quantidade e da ativação da FAK nos ossos de animais estimulados com o equipamento de USbp "desligado", apesar de menor do que nos animais estimulados com o equipamento ligado, indica que o estresse "muscular" deve interferir na atividade de proteínas mecanossensíveis no tecido "ósseo"(67,68).

\section{Considerações finais}

A mecanotransdução é um fenômeno que ocorre constantemente no tecido ósseo, apresentando repercussões clínicas importantes e que devem ser valorizadas. No entanto, por se tratar de um fenômeno complexo e que envolve vários tipos de moléculas, organizadas em múltiplos sistemas que interagem entre si, ainda é pouco compreendido. O estudo detalhado de todas as fases envolvidas na cadeia dos eventos moleculares é essencial para que se possa entender o todo e atuar de modo sistemático nesse processo, que é aparentemente ainda muito complexo.

\section{REFERÊNCIAS}

1. Dauty M, Verbe BP, Maugars Y, Dubois C, Mathe JF. Supralesional and sublesional bone mineral density in spinal cord-injured patients. Bone. 2000;27(2):305-9.

2. Epstein S, Inzerillo AM, Caminis J, Zaidi M. Disorders associated with acute rapid and severe bone loss. J Bone Miner Res. 2003;18(12):2083-94.

3. Frey-Rindova P, de Bruin ED, Stüssi E, Dambacher MA, Dietz V. Bone mineral density in upper and lower extremities during 12 months after spinal cord injury measured by peripheral quantitative computed tomography. Spinal Cord. 2000;38(1):26-32.

4. LeBlanc A, Shackelford L, Schneider V. Future human bone research in space. Bone. 1998;22(5 Suppl.):113S-6S.

5. Vico L, Lafage-Proust MH, Alexandre C. Effects of gravitational changes on the bone system in vitro and in vivo. Bone. 1998;22(5 Suppl.):95S-100S.

6. Vico L, Collet P, Guignandon A, Lafage-Proust MH, Thomas T, Rehaillia M, et al. Effects of long-term microgravity exposure on cancellous and cortical weightbearing bones of cosmonauts. Lancet. 2000;355(9215):1607-11.

7. Bailey DA, Mckay HA, Mirwald RL, Crocker PRE, Faulkner RA. A six-year longitudinal study of the relationship of physical activity to bone mineral accrual in growing children: The University of Saskatchewan bone mineral accrual study. J Bone Miner Res. 1999;14(10):1672-9.

8. Duncan RL, Turner $\mathrm{CH}$. Mechanotransduction and the functional response of bone to mechanical strain. Calcif Tiss Int. 1995;57(5):344-58.

9. Harada S, Rodan GA. Control of osteoblast function and regulation of bone mass. Nature. 2003;423(6937):349-55.

10. Hughes-Fulford M. Signal transduction and mechanical stress. Sci STKE. 2004;(249):RE12.

11. Boutahar N, Guignandon A, Vico L, Lafage-Proust MH. Mechanical strain on osteoblasts activates autophosphorylation of focal adhesion kinase and prolinerich tyrosine kinase 2 tyrosine sites involved in ERK activation. J Biol Chem. 2004;279(29):30588-99.

12. Scott A, Khan KM, Duronio V, Hart DA. Mechanotransduction in human bone in vitro cellular physiology that underpins bone changes with exercise. Sports Med. 2008;38(2):139-60.

13. Nomura S, Takano-Yamamoto T. Molecular events caused by mechanical stress in bone. Matrix Biology. 2000;19(2):91-6.

14. Fritton SP, Kenneth JM, Rubin CT. Quantifying the strain history of bone: spatial uniformity and self-similarity of low-magnitude strains. J Biomech. 2000;33(3)317-25.

15. Rubin CT, Lanyon LE. Regulation of bone formation by applied dynamic loads. J Bone Joint Surg Am. 1984;66(3):271-80.

16. You L, Cowin SC, Schaffler MB, Weinbaum S. A model for strain amplification in the actin cytoskeleton of osteocytes due to fluid drag on pericellular matrix. J Biomech. 2001;34(11):1375-86

17. Buckwalter JA, Glimcher MJ, Cooper RR, Recker R. Bone biology. I: Structure, blood supply, cells, matrix, and mineralization. Instr Course Lect. 1996;45:371-86.

18. Buckwalter JA, Glimcher MJ, Cooper RR, Recker R. Bone biology. II: Formation, form, modeling, remodeling, and regulation of cell function. Instr Course Lect. 1996;45:387-99.

19. Kapur S, Baylink D, Lau K-HW. Fluid flow shear stress stimulates human osteoblast proliferation and differentiation through multiple interacting and competing signal transduction pathways. Bone. 2003;32(3):241-51.

20. Liedbert A, Kaspar D, Blakytny R, Claes L, Ignatius A. Signal transduction pathways involved in mechanotransduction in bone cells. Biochem Biophys Res Comm. 2006;349(1):1-5.

21. Norvell SM, Alvarez M, Bidwell JP, Pavalko FM. Fluid shear stress induces $\beta$ catenin signaling in osteoblasts. Calcif Tiss Int. 2004;75(5):396-404.

22. Bonewald LF. Mechanosensation and transduction in osteoblasts. Bonekey Osteovision. 2006;3(10):7-15.

23. Cherian PP, Siller-Jakson AJ, Gu S, Wang X, Bonewald LF, Sprague E, et al. Mechanical strain opens connexin 43 hemichannels in osteocytes: a novel mechanism for the release of prostaglandin. Mol Biol Cell. 2005;(16)7:3100-6. 
24. Plotkin LI, Mathov I, Aguirre JI, Parfitt AM, Manolagas SC, Bellido T. Mechanical stimulation prevents osteocyte apoptosis: requirement of integrins, Src kinases, and ERKs. Am J Physiol Cell Physiol. 2005;289(3):633-43

25. Klein-Nulend J, van der Plas A, Semeins CM, Ajubi NE, Frangos JA, Nijweide $\mathrm{PJ}$, et al. Sensitivity of osteocytes to biomechanical stress in vitro. FASEB J. 1995;9(5):441-5.

26. Taylor AF, Saunders MM, Shingle DL, Cimbala JM, Zhou Z, Donahue HJ. Mechanically stimulated osteocytes regulate osteoblastic activity via gap junctions. Am J Physiol Cell Physiol. 2007;292(1):C545-52.

27. Li Z, Yang G, Khan M, Stone D, Woo SL-Y, Wang JH-C. Inflammatory response of human tendon fibroblasts to cyclic mechanical stretching. Am J Sports Med. 2004;32(2):435-40.

28. Hsu H-C, Fong Y-C, Chang C-S, Hsu C-J, Hsu S-F, Lin J-G, et al. Ultrasound induces cyclooxygenase-2 expression through integrin, integrin-linked kinase, Akt, NF-kB and p300 pathway in human chondrocytes. Cell Signal. 2007;19(11):2317-28.

29. Gupta V, Grande-Allen KJ. Effects of static and cyclic loading in regulating extracellular matrix synthesis by cardiovascular cells. Cardiovasc Res. 2006;72(3):375-83

30. Chen K-D, Li Y-S, Kim M, Li S, Yuan S, Chien S, et al. Mechanotransduction in response to shear stress. Roles of receptor tyrosine kinases, integrins, and Shc. J Biol Chem. 1999;274(26):18393-400.

31. Goldspink G. Changes in muscle mass and phenotype and the expression of autocrine and systemic growth factors by muscle in response to stretch and overload. J Anat. 1999;194(3):323-34

32. Fukada E, Yasuda I. On the piezoeletric effect of bone. J Phys Soc Japan. 1957;12(10):1158-62.

33. Butcher MT, Espinoza NR, Cirilo SR, Blob RW. In vivo strains in the femur of river cooter turtles (Pseudemys concinna) during terrestrial locomotion: tests of force-platform models of loading mechanics. J Exp Biol. 2008;211(Pt 15):2397-407

34. Qin YX, Lin W, Rubin C. The pathway of bone fluid flow as defined by in vivo intramedullary pressure and streaming potential measurements. Ann Biomed Eng. 2002;30(5):693-702

35. Genetos DC, Geist DJ, Liu D, Donahue HJ, Duncan RL. Fluid shear-induced ATP secretion mediates prostaglandin release in MC3T3-E1 osteoblasts. J Bone Miner Res. 2005;20(1):41-9.

36. Riddle RC, Donahue HJ. From streaming-potentials to shear stress: 25 years of bone cell mechanotransduction. J Orthop Res. 2009;27(2):143-9.

37. Salter DM, Robb JE, Wright MO. Electrophysiological responses of human bone cells to mechanical stimulation: evidence for specific integrin function in mechanotransduction. J Bone Miner Res. 1997;12(7):1133-41.

38. Salter DM, Wallace WH, Robb JE, Caldwell H, Wright MO. Human bone cell hyperpolarization response to cyclical mechanical strain is mediated by an interleukin-1 beta autocrine/paracrine loop. J Bone Miner Res. 2000;15(9):1746-55

39. Yokota $\mathrm{H}$, Tanaka SM. Osteogenic potentials with joint-loading modality. J Bone Miner Metab. 2005;23(4):302-8.

40. Gronthos S, Stewart K, Graves SE, Hay S, Simmons PJ. Integrin expres sion and function on human osteoblast-like cells. J Bone Miner Res. 1997;12(8):1189-97.

41. Sinha RK, Tuan RS. Regulation of human osteoblast integrin expression by orthopaedic implant materials. Bone. 1996;18(5):451-7.

42. Bennett JH, Carter DH, Alavi AL, Beresford JN, Walsh S. Patterns of integrin expression in a human mandibular explant model of osteoblast differentiation. Arch Oral Biol. 2001;46(3):229-38.

43. Van Der Flier A, Sonnenberg A. Functions and interactions of integrins. Cell Tiss Res. 2001;305(3):285-98.

44. Lee HS, Millward-Sadler SJ, Wright MO, Nuki G, Salter DM. Integrin and mechanosensitive ion channel-dependent tyrosine phosphorylation of focal adhesion proteins and beta-catenin in human articular chondrocytes after mechanical stimulation. J Bone Miner Res. 2000;15(8):1501-9.

45. Pommerenke H, Schmidt C, Dürr F, Nebe B, Lüthen F, Muller P, et al. The mode of mechanical integrin stressing controls intracellular signaling in osteoblasts. J Bone Miner Res. 2002;17(4):603-11.
46. Tang $\mathrm{CH}$, Yang RS, Huang TH, Lu DY, Chuang WJ, Huang TF, et al. Ultrasound stimulates cyclooxygenase-2 expression and increases bone formation through integrin, FAK, phosphatidylinositol 3-kinase and Akt pathway in osteoblasts. Mol Pharmacol. 2006;69(6):2047-57.

47. Cornillon J, Campos L, Guyotat D. Focal adhesion kinase (FAK), a multifunctional protein. Med Sci (Paris). 2003;19(6-7):743-752.

48. Giancotti FG, Rouslahti E. Integrin signaling. Science. 1999;285(5430):1028-32.

49. Guan J. Focal adhesion kinase in integrin signaling. Matrix Biol. 1997;16(4):195-200.

50. Kawamura N, Kugimiya F, Oshima Y, Ohba S, Ikeda T, Saito T, et al. Akt1 in osteoblasts and osteoclasts controls bone remodeling. PLoS One. 2007;2(10): e1058.

51. Mitra SK, Hanson DA, Schlaepfer DD. Focal adhesion kinase: in command and control of cell motility. Nature. 2005;6(1):56-68.

52. Parsons JT. Focal adhesion kinase: the first ten years. J Cell Sci. 2003; 116(Pt 8):1409-16.

53. Raucci A, Bellosta P, Grassi R, Basilico C, Mansukhani A. Osteoblast proliferation or differentiation is regulated by relative strengths of opposing signaling pathways. J Cell Physiol. 2008;215(2):442-51.

54. Schlaepfer DD, Jones KC, Hunter T. Multiple Grb2-mediated integrin-stimulated signaling pathways to ERK2/mitogen-activated protein kinase: summation of both c-Src- and focal adhesion kinase-initiated tyrosine phosphorylation events. Mol Cell Biol. 1998;18(5):2571-85.

55. Donahue HJ. Gap junctions and biophysical regulation of bone cell differentiation. Bone. 2000; 26(5):417-22.

56. Jiang JX, Siller-Jackson AJ, Burra S. Roles of gap junctions and hemichannels in bone cell functions and in signal transmission of mechanical stress. Front Biosci. 2007;12:1450-62.

57. AIUM. Mechanical bioeffects from diagnostic ultrasound: AIUM consensus statements. American Institute of Ultrasound in Medicine. J Ultrasound Med. 2000;19(2):68-168

58. WFUMB. World Federation for Ultrasound in Medicine and Biology Symposium on safety of ultrasound in medicine. Ultrasound Med Biol. 1998;(24 Suppl 1): S1-58.

59. Azuma Y, Ito M, Harada Y, Takagi H, Ohta T, Jingushi S. Low-intensity pulsed ultrasound accelerates rat femoral fracture healing by acting on the various cellular reactions in the fracture callus. J Bone Miner Res. 2001.16(4):671-680.

60. Duarte LR. The stimulation of bone growth by ultrasound. Arch Orthop Trauma Surg. 1983;101(3):153-9.

61. Heckman JD, Ryaby JP, McCabe J, Frey JJ, Kilcoyne RF. Acceleration of tibial fracture-healing by non-invasive, low-intensity pulsed ultrasound. J Bone Joint Surg Am. 1994;76(1):26-34.

62. Jingushi S, Mizuno K, Matsushita T, Itoman M. Low-intensity pulsed ultrasound treatment for postoperative delayed union or nonunion of long bone fractures. J Orthop Sci. 2007;12(1):35-41.

63. Kristiansen TK, Ryaby JP, McCabe J, Frey JJ, Roe LR. Accelerated healing of distal radial fractures with the use of specific, low-intensity ultrasound. A multicenter, prospective, randomized, double-blind, placebo-controlled study. J Bone Joint Surg Am. 1997;79(7):961-73.

64. Mayr E, Frankel V, Rüter A. Ultrasound - an alternative healing method for nonunions? Arch Orthop Trauma Surg. 2000;120(1-2):1-8.

65. Shimazaki A, Inui K, Azuma Y, Nishimura N, Yamano Y. Low intensity pulsed ultrasound accelerates bone maturation in distraction osteogenesis in rabbits. J Bone Joint Surg Br. 2000;82(7):1077-82.

66. Wang SJ, Lewallen DG, Bolander ME, Chao EY, Ilstrup DM, Greenleaf JF. Low intensity ultrasound treatment increases strength in a rat femoral fracture model. J Orthopc Res. 1994;12(1):40-7.

67. Gusmão CVB, Pauli JR, Belangero WD. Efeito do ultra-som de baixa potência na expressão da FAK (focal adhesion kinase), ERK-2 (extracellular signalregulated kinase-2) e IRS-1 (insulin receptor substrate-1) no osso in vivo. In: Anais do XVI Congresso Médico Acadêmico da Unicamp; 2007.

68. Gusmão CVB, Pauli JR, Belangero WD. O ultra-som de baixa potência altera a cinética da FAK (focal adhesion kinase), ERK-1/2 (extracellular signal-regulated kinase-1/2) e Akt em tíbias de ratos sem fratura. In: Anais do XVII Congresso Médico Acadêmico da Unicamp; 2008. 